\title{
Problems and Suggestions of Chinese Family Education
}

\section{Taking Two Movies as Examples for Analysis}

\author{
Yixuan Dai ${ }^{1, a}$ \\ ${ }^{1}$ Contemporary Media Practice, University of Westminster, London, HA1 3TP, United Kingdom \\ ${ }^{a}$ Email Address: w1738356@my.westminster.ac.uk
}

\begin{abstract}
Family education has an important influence on children's growth process and future development. In China, common family education problems include the impact of parental divorce on children's psychology and personality, the growth of children in single-parent families, and the link between family education and school education. In recent years, through the emergence of educational films, the problem of family education has been widely concerned by the society. This essay analyzes two educational films and summarizes the existing problems of Chinese family education by comparing the plots and characters of the films and connecting them with relevant research on Chinese family education. In view of the social situation and trend of increasing divorce rate, this paper puts forward some suggestions, including parents should use correct family education methods, fulfill parental obligations, and Chinese society needs to consider the mainstream idea of educational environment.
\end{abstract}

Keywords: Family education, education film, educational environment, the divorce rate

\section{INTRODUCTION}

Education-themed films tell stories related to children or teenagers and profoundly convey the real concept and significance of education in the minds of filmmakers. In the modern education environment of China, the idea of not letting children lose at the starting line has become a trend, which is concretively shown in parents rushing with their children in various extracurricular tutoring classes on weekends. In an environment where scores determine heroes, children and their parents find it difficult to bear the huge educational pressure. That, in turn, results in children's talents and interests being eclipsed by spoon-feeding. This essay analyses and compares two Chinese education-themed films, Looking Up and Einstein \& Einstein. This will summarizes the educational views, themes, and meanings expressed in the films. This essay also connects the educational theme in the film, and the current educational environment in China, specifically analyses the social reality problems reflected in the film and gives some relevant suggestions through data analysis.

\section{CHINESE EDUCATION AND SOCIETY}

The first problem is that test-oriented education is no longer in line with the development needs of the times, but it is still the mainstream education method in China. The biggest problem with test-oriented education is that academic performance is the only criterion for judging a child's quality. For one thing, some children will be wrongly evaluated because their skills are limited. For another, parents will pay too much attention to their children's academic performance. These will increase the stress of the child. A study by Leung \& Shek (2011) on parents' expectations for their children's academic performance and other aspects shows that although these concerns and expectations help students make continuous progress, they also bring great psychological pressure to them [6]. Wang \& Hepper (2002) studied the impact of parental expectations on students' mental health. The research results show that living up to parents' expectations has become an important factor in predicting adolescents' psychological distress [11]. Therefore, parents need to correctly express their expectations of their children. In addition, parents also need to consciously pay attention to their children's own 
talents, and provide children with space to develop their talents.

The second social phenomenon that people should pay attention to is the increasing divorce rate in China. The research conclusion of $\mathrm{Li}$ (2020) shows that China's divorce rate is on the rise due to various factors, including the increase of work pressure [7]. What single-parent families share in common is the lack of one parent's supervision and care for children [7]. Furthermore, Liu (2011) pointed out that children from single-parent families have poor mental health, more behavioural problems, and a higher probability of depression [8]. In particular, girls are less likely to accept the restructured family, are less able to adapt to the restructured family, and are more prone to negative emotions and behaviours [4]. Zhang (2019) also concluded that children living with single mothers perform better, while children with single fathers and reorganized families generally have lower academic performance and lack of subjective well-being [12]. However, such negative influence does not only appear in the growth of children from single-parent families. Zhang (2019) believes that in intact families, frequent quarrels between parents will also negatively influence children [12]. What is more, $\mathrm{Hu}$ (2014) believes that high parental participation will produce positive results, such as more accurate judgment in learning direction according to social needs and educational environment [3]. Similarly, An et al. (2019) showed that many studies have confirmed that parental participation in school education positively impacts students' academic performance. Different ways of parental participation and educational level have other impacts on children's academic performance [1]. Hence, it is essential that parents participate in their children's education in an appropriate capacity.

Thirdly, paying attention to family education is an essential and essential matter in the development of children [9]. Family education refers to the education a person receives in the particular social structure of the family, including conscious knowledge imparted, moral education and deliberate cultivation of the family life atmosphere [2]. In the traditional concept of China, family education is the education carried out by parents (most notably, parents) to their children in family life. Family education will not only have an impact on children's character but also on school education, because family education is the foundation of the school and social education, which is lifelong and unique [10]. Children receive home education is the earliest and lasts the longest. Family education belongs to individualized education, not systematic education, and the scope involved has not been clearly defined. However, Chinese school education is phased, which is oriented to most students, and the content of education is also based on scientific and cultural knowledge.

\section{COMPARISON OF FILM PLOT}

Looking Up tells a family story about a father and son who finally gained love and growth despite not seeing each other for many years. Since childhood, Ma Fei has dreamed of being an astronaut, but his father, Ma Haowen, was wrongfully imprisoned and lacked company and discipline, becoming a typical rebellious student. Everyone around Ma Fei, including his mother, thinks he is stupid. However, his father, Ma Haowen, has always encouraged him and bet with the teacher in charge, to Ma Fei from the bottom of the grades into good students with excellent character and learning. Later, the father uniquely gave his son extra lessons and named the school he and his son set up galaxy school.

Einstein \& Einstein tells the coming-of-age story of Li Wan, an adolescent girl. The theme of the educational environment in the film is typical Chinese education. That is, children obey their parents' arrangements. In the film, $\mathrm{Li}$ was brought up by his grandparents and lacked the companionship of his parents. Her father hopes to reconcile and communicate with her through a pet dog. However, in the process of Li get along with that pet dog, father and other relatives coax Li again and again. For example, the cause of the lost of the pet dog, deceiving Li with a new dog, and telling her to find the pet dog. Lies, cajoling and violence trigger conflicts, so the growing process and family environment of the young girl Li Wan is not beautiful and sincere.

The two films have something in common. First of all, both films are based on the mainstream idea of China's education environment. Children obey their parents' arrangement, parents have great expectations for their children, and they should not lose at the starting line. The film emphasizes the importance of test scores and shows that students have to drop out of school for poor grades and have to go to cram schools during holidays. Grades even become the most important criterion to distinguish good students from bad ones, which also brings tremendous study pressure on students from when they are very young. Secondly, the children in the film all live in single-parent families and have experienced family changes when their parents divorced at an early age. The incomplete family of origin makes the children more likely to be ignored by their parents and even not get complete love in their growth. Ma Fei in Milky Way cram school is laughed at by his classmates at school because of his parents' lack of companionship. After her parents divorced, Li Wan leaves her parents and lives by her grandparents. Li's mother rarely contacts her. Her father is busy with his work all the year round and take Li home after he builded up a new family. A teenage girl in her rebellious phase has difficulty finding her place among unfamiliar family. Thirdly, the family education in the film has an impact on children's school education. Ma Fei in 
Looking Up suffers from mental health problems due to insufficient home education from his mother, which results in his performance in school is different from other students. However, Li, from Einstein \& Einstein, lives in a patriarchal family where many of her choices are made by her father. For example, Li Wan is talented and interested in physics, but she is forced to join an English study group.

Meanwhile, there are some differences in the two films' plots, which is mainly reflected in the differences in fathers' educational concepts and attitudes towards their children. After his reunion with his son, Ma Fei's father encouraged him with sincere love and companionship and stimulated his interest in learning and thinking. On the contrary, Li's father arbitrarily changes her interest choice. He uses rude language and action to treat his daughter, when his daughter is "not sensible". What is more, he hits his daughter, when he is angry. He dominated his daughter's choice with his thinking, regardless of her real feelings.

\section{EDUCATIONAL PROPOSAL}

The first suggestion made in this paper is that parents and society need to think about the forms and ways of family education. The family is the basic unit of society. It is necessary to build a good family education environment to promote the healthy development of children from single-parent families. In China, many parents attach great importance to family education, but they emphasize monitoring their children's studies, which is not the essence of family education. In the movie Einstein \& Einstein, Li Wan's father uses the wrong parenting method. He lied and cheated Li Wan many times. According to his wishes, he arranged children and even used violence. All this negatively affected Li's psychology and caused the destructive relationship between father and daughter. Life is not a competition. Valuing education is not spying on children. The growth process should not be full of training and strict requirements. Encouragement and companionship should be essential themes. The most fundamental and effective way of family education is to teach by example rather than by words. Parents' behaviour influences their children's current and future behaviour. It seems that the influence of family is more deeply rooted than that of school, especially in personality and way of thinking. Good family education is essential for children to get along well with others and develop a correct sense of self. If the family education method is improper, children from single-parent families will have problems in learning, self-awareness, social communication, personality development and other aspects. Learning mode of education, adopting this way of parents can better guide children to think, share children's inner feelings and help children form independent personality. The children cultivated by this kind of education are often independent, good at thinking, creative, and getting along with others.

Chinese education is based on the increasing number of single-parent families in China, how to prevent the children from these families from being negatively affected in character cultivation and mental health. The second suggestion is that parents should pay more attention to accompany their children and fulfil their parental duties. According to the rising divorce rate in China, the number of divorced families is increasing. Due to the incomplete family composition, it is difficult for children to get complete family education and parents' care, which is detrimental to their growth and development. Jiang, Xia \& Ji (2008) believes that the increasing number of single-parent families in China cannot be ignored [5]. Zhang (2019) established a research group on Chinese families, and evidence shows that divorced single parents have become more and more common in China since the beginning of the $21 \mathrm{st}$ century [12]. The data in figure 1 clearly show that the divorce rate in China rose from the lowest to the second place, only lower than that in the United States. Table 1 shows the proportions of different family structures in China. The percentage of intact families shows a declining trend. It is vital for parents of single-parent families to recognize that their children are affected by the imperfect family structure and participate in their children's development in a proper capacity. That can help children from single-parent families get more sense of happiness and security. It is also of great significance to build a harmonious social environment in the future.

The last suggestion is about the mainstream ideas and forms of Chinese education, whether there is a better model to replace the exam-oriented education and give students more choices and opportunities to discover their talents. The traditional exam-oriented education model leads to great pressure on students and leads to a tremendous burden on parents. The best way to change might be to follow the principle of teaching students in accordance with their aptitude, not just mandatory for all students to learn the same academic knowledge, have stiff schooling. 


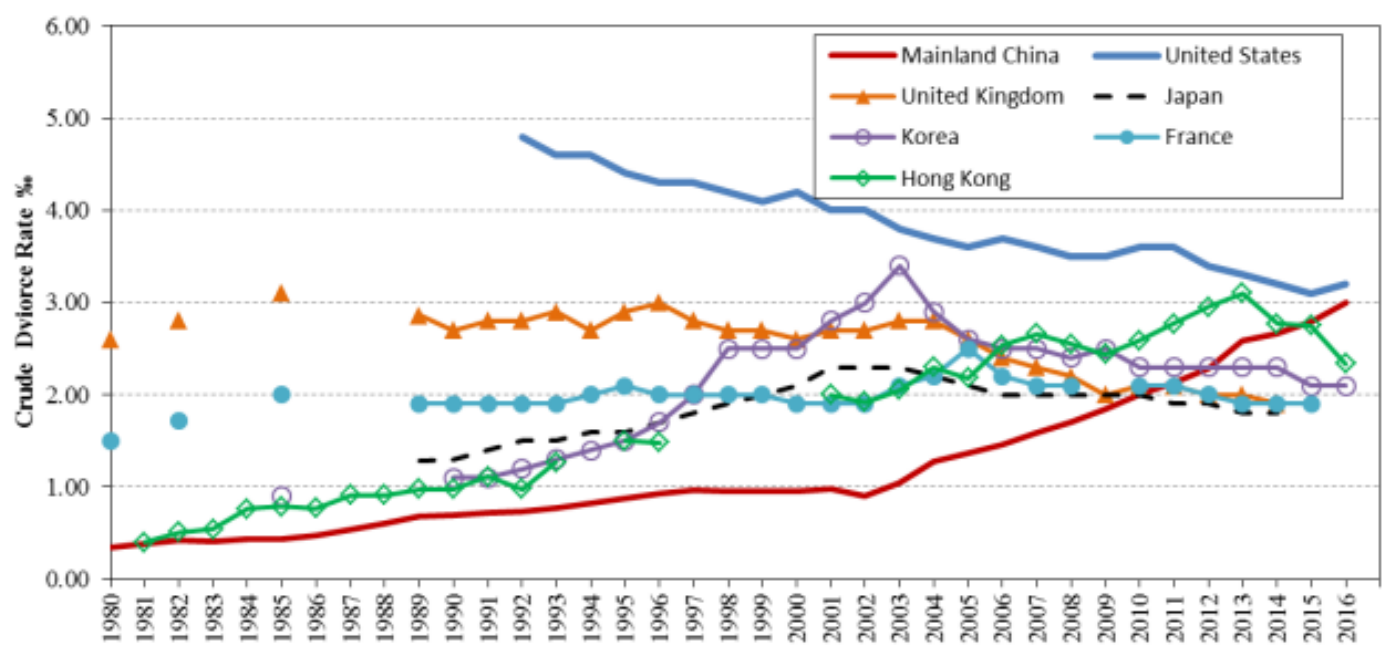

Figure 1. Crude divorce rates in selected countries/region [12]

Table 1. Distribution of children aged 10-15 from four types of families (\%), CFPS 2010-2014 [12]

\begin{tabular}{llll}
\hline Family structure & 2010 & 2012 & 2014 \\
\hline Intact two-parent families & 96.84 & 95.86 & 94.57 \\
Single-mother families & 0.47 & 0.51 & 0.44 \\
Single-father families & 0.93 & 1.30 & 1.61 \\
Stepparent families & 1.77 & 2.32 & 3.38 \\
Total & 100.00 & 100.00 & 100.00 \\
$(\mathrm{~N})$ & $(4,077)$ & $(3,700)$ & $(3,667)$ \\
\hline
\end{tabular}

Notes: Stepparent families refer to families with a stepparent and a post-divorced remarried biological parent.

\section{CONCLUSION}

To sum up, the theme of this paper is to think about relevant education problems and the social status quo by summarizing and analysing two Chinese education-themed films. Firstly, by comparing the plots and characters of Looking Up and Einstein \& Einstein, it is found that the similarities between the two films are typical mainstream Chinese education ideas, and the single parent family influences children's personality and psychology. The differences between the two films are mainly reflected in parents' different family education methods, which have different influences on children's growth process, academic performance, and life direction. After finding the above views, this paper considers the social reality reflected in the film based on the Chinese educational environment. It mainly includes the Chinese educational thought that exam-oriented education and children follow parents' arrangement as the mainstream, and increased rates of single-parent or reorganized families, whose children are more prone to negative emotions and behaviours. A wide range of family education is the foundation of school education. Encouragement and companionship are necessary factors in establishing a good growth environment. Parents' extreme and impatient behaviour will produce estrangement with their children and lead to ineffective communication. Finally, this essay puts forward three suggestions for the above education problems. First of all, thinking about the form and way of family education is a problem that families and society need to consider. Learning education can effectively help children learn to think and form independent character. Secondly, with the high and rising divorce rate in Chinese families, children's personality and psychology should be less negatively affected as much as possible. Thirdly, China's exam-oriented education system should be considered whether it is reasonable enough. Perhaps an educational environment with more forms of education can give more children the opportunity to achieve and discover their talents.

\section{REFERENCES}

[1] An, G. et al. A Study on the Effects to Students' STEM Academic Achievement with Chinese Parents' Participative Styles in School Education. Educational Sciences: Theory \& Practice, 2019, 19(1).

[2] Colletta, N. 3 Family, Church, and Community as Agents of Moral Education. University of Hawaii Press. 2021. 
[3] Hu, J. Chinese Parents' Hopes for their only Children: A Transition Program Case Study. Iowa State University. 2014.

[4] Jia. Subjective Well-being and Family Functioning among Adolescents Left Behind by Migrating Parents in Jiangxi Province, China. 2018.

[5] Jiang, Z., Xia, Y. \& Ji, L. An investigation and analysis of childrens education of Qingdao Single-parent families. 2008.

[6] Leung, J.T.Y. \& Shek, D.T.L. Expecting my child to become "dragon"-development of the Chinese Parental Expectation on Child's Future Scale. From the journal. 2011.

[7] Li, M. A Longitudinal Study of the Long-Term Predictors of China's Divorce Rate. Marriage \& Family Review, 2020, 56(3).

[8] Liu. A survey on the mental health status and family environment of single-parent undergraduates. 2011.

[9] Masten \& Barnes. Resilience in Children: Developmental Perspectives. Children, 2018, 5(7): 98.

[10] Soleimanpour, S., Geierstanger, S.G. \& Brindis, C.D. Adverse Childhood Experiences and Resilience: Addressing the Unique Needs of Adolescents. 2017, 17(7): 108-114.

[11] Wang L.F.\& Hepper P.P. Assessing the Impact of Parental Expectations and Psychological Distress on Taiwanese College Students. The Counseling Psychologist. 2002.

[12] Zhang C. Are Children from Divorced Single-Parent Families Disadvantaged? New Evidence from the China Family Panel Studies. Chinese Sociological Review, 2019, 84-114. 